\title{
Increases in Fentanyl-Related Overdose Deaths — Florida and Ohio, 2013-2015
}

Alexis B. Peterson, $\mathrm{PhD}^{1,2,3}$; R. Matthew Gladden, $\mathrm{PhD}^{2}$; Chris Delcher, $\mathrm{PhD}^{4}$; Erica Spies, $\mathrm{PhD}^{1,5}$; Amanda Garcia-Williams, PhD 1,5 ; Yanning Wang, MS ${ }^{4,6}$; John Halpin, $\mathrm{MD}^{2}$; Jon Zibbell, $\mathrm{PhD}^{2}$; Carolyn Lullo McCarty, $\mathrm{PhD}^{1,7,8}$; Jolene DeFiore-Hyrmer, $\mathrm{MPH}^{8}$; Mary DiOrio, MD ${ }^{8}$; Bruce A. Goldberger, PhD 6

In March and October 2015, the Drug Enforcement Administration (DEA) and CDC issued nationwide alerts identifying fentanyl, particularly illicitly manufactured fentanyl (IMF), as a threat to public health and safety $(1,2)$. IMF is pharmacologically similar to pharmaceutical fentanyl (PF), but is unlawfully produced in clandestine laboratories, obtained via illicit drug markets, and includes fentanyl analogs. Fentanyl is a synthetic opioid 50-100 times more potent than morphine and approved for the management of surgical/postoperative pain, severe chronic pain, and breakthrough cancer pain.* DEA's National Forensic Laboratory Information System (NFLIS) collects drug identification results from drug cases analyzed by federal, state, and local forensic laboratories throughout the United States. ${ }^{\dagger}$ In 2014, 80\% of fentanyl submissions (i.e., drug products obtained by law enforcement that tested positive for fentanyl) in NFLIS were identified from 10 states, including Florida and Ohio (2), and seven of these 10 states reported sharp increases in fentanyl-related overdose deaths (fentanyl deaths) (3). This report presents findings of increased fentanyl deaths during 2013-2015 from investigations conducted by the University of Florida and the Ohio Department of Public Health, in collaboration with CDC. Analyses examined the association between trends in fentanyl-related law enforcement submissions and fentanyl deaths and describes groups at risk for fentanyl death using medical examiner and coroner reports. The marked increases in fentanyl death in Florida and Ohio during 2013-2015 were closely associated with parallel increases in fentanyl submissions, with the largest impact on persons who use heroin, consistent with reports that IMF is commonly mixed with or sold as heroin $(1,4)$. In Ohio, circumstances associated with fentanyl deaths included a current diagnosed mental health disorder $^{\S}$ and recent release from an institution such as a jail, rehabilitation facility, or hospital.

Three different analyses are reported. The first analysis compared trends in fentanyl deaths, fentanyl submissions, and fentanyl prescribing during January 2013-June 2015, using 1) medical examiner and coroner reports in Florida and death certificates in Ohio, 2) NFLIS data in both states, and

\footnotetext{
*http://www.accessdata.fda.gov/scripts/cder/drugsatfda/index.cfm?fuseaction=Search. SearchAction\&SearchTerm $=$ fentanyl\&SearchType $=$ BasicSearch .

$\dagger$ http://www.deadiversion.usdoj.gov/nflis/.

$\$$ The decedent had been identified during the death investigation as having a mental health disorder or syndrome listed in the Diagnostic and Statistical Manual, Version IV (DSM-IV). Alcohol and other substance dependence are excluded from this variable.
}

3) prescription drug monitoring program data (E-FORCSE in Florida and OARRS in Ohio**) that track the prescribing and dispensing of controlled substances (schedules II, III, and IV drugs). Data on overdose deaths involving fentanyl analogs were also available for the first half of 2015 in Florida. The second analysis used medical examiner data to compare demographic and toxicologic characteristics of fentanyl deaths in Florida before (2010-2012) and during (2013-2014) the marked increase in fentanyl submissions. For the third analysis, the Ohio Department of Health conducted an in-depth review of medical examiner and coroner reports of fentanyl deaths, including toxicology panel findings, medical history, drug abuse history, and overdose scene characteristics occurring in 14 high-burden counties (Butler, Clark, Clermont, Cuyahoga, Fayette, Hamilton, Lucas, Miami, Montgomery, Ross, Scioto, Stark, Summit, and Warren) in 2014. These counties were selected based on a high number and/or rate of fentanyl deaths and geographic diversity (urban versus rural) and accounted for $73 \%$ of Ohio's fentanyl deaths reported on death certificates during January-December 2014. Data from Ohio's medical examiners and coroners were abstracted from the Ohio Violent Death Reporting System.

During 2013-2014, fentanyl submissions increased 494\% in Florida (from 33 to 196) and 1,043\% in Ohio (from 109 to $1,246)$, concurrent with a $115 \%$ increase in fentanyl deaths in Florida (from 185 to 397 ) and a 526\% increase in Ohio (from 84 to 526) (Figure). In Florida, fentanyl submissions and fentanyl deaths gradually increased during May-November 2014, with a sharp increase during December 2014-February 2015, before returning to levels consistent with July-November 2014 during March-June 2015. Ohio's fentanyl deaths and fentanyl submissions spiked during November 2013-March 2014, followed by a sharp decline in April-May 2014, and then a gradual and continuous rise during June 2014-May 2015. In contrast, fentanyl prescription rates for the full year increased only 5\% in Florida (from 19.3 in 2013 to 20.3 in 2014 per 1,000 population) and declined $7 \%$ in Ohio over the same period (from 21.6 to 20.1) (Figure).

Florida's fentanyl death rates increased approximately 250\% among persons aged 14-34 years from 2010-2012

\footnotetext{
Additional information regarding the Electronic-Florida Online Reporting of Controlled Substance Evaluation Program (E-FORCSE) is available at http://www.floridahealth.gov/statistics-and-data/e-forcse/.

** Additional information regarding the Ohio Automated Rx Reporting System (OARRS) is available at https://www.ohiopmp.gov/Portal/Default.aspx.
} 
Please note: An erratum has been published for this issue. To view the erratum, please click here.

Morbidity and Mortality Weekly Report

FIGURE. Number of fentanyl-related law enforcement submissions* and overdose deaths, and rate of fentanyl prescriptions — Florida and Ohio, January 2013-June 2015

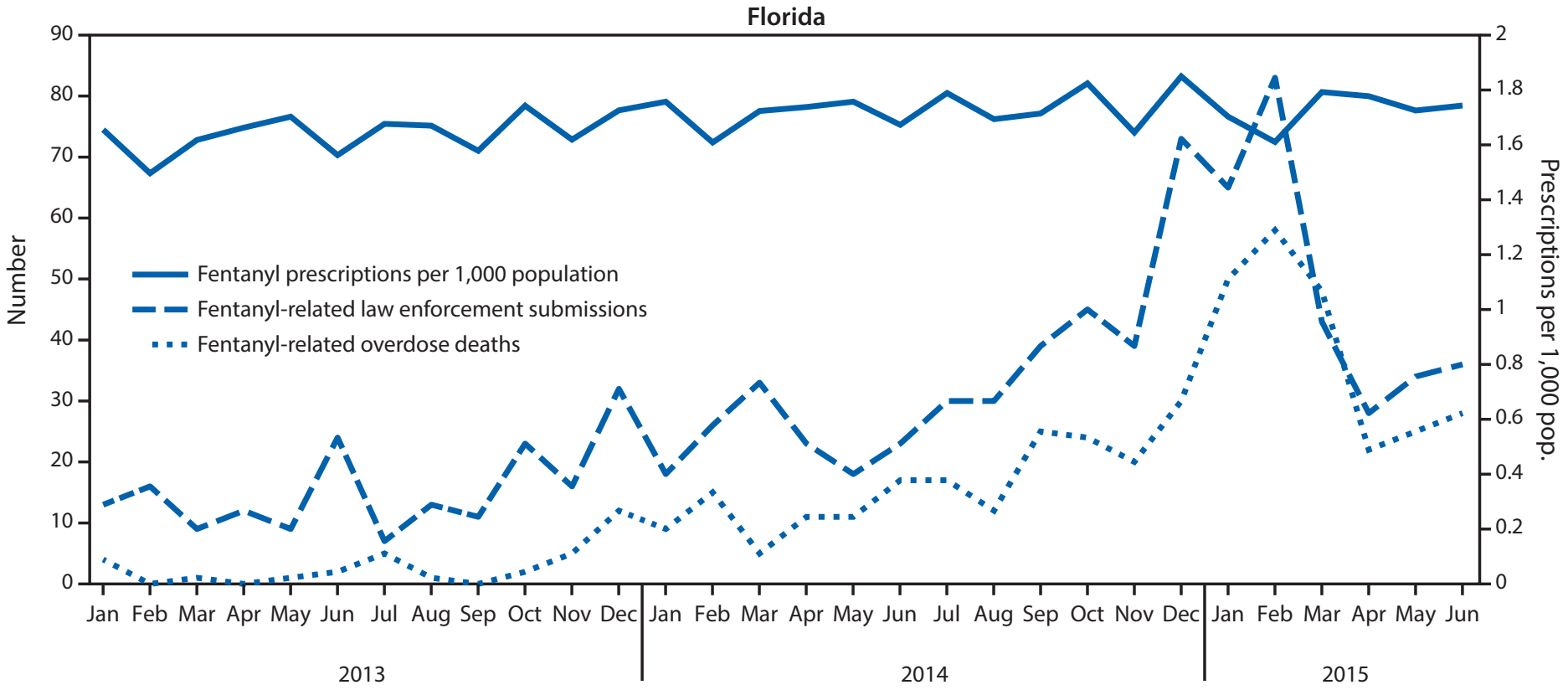

Year/Month

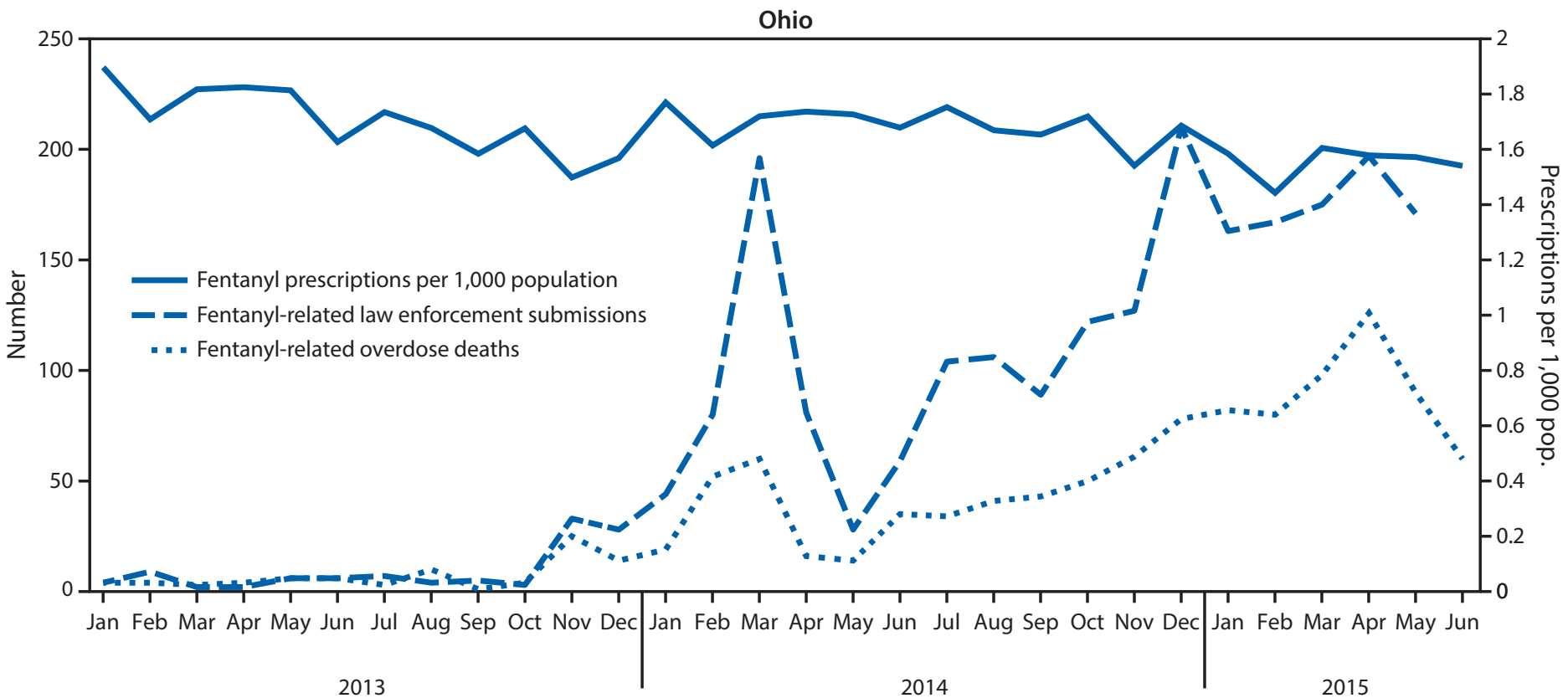

Year/Month

* Drug products obtained by law enforcement that tested positive for fentanyl. Florida submissions data downloaded April 20, 2016, and Ohio data downloaded November 17, 2015, from the Drug Enforcement Administration's National Forensic Laboratory Information System.

to 2013-2014, followed by increases among persons aged $35-50$ years, males, and whites of $143.2 \%, 162.9 \%$, and $122.5 \%$, respectively (Table 1). The highest fentanyl death rates in Florida during 2013-2014 occurred among persons aged 26-34 years (3.2 per 100,000$)$ and $35-50$ years (2.9), males (2.5), and whites
(2.1). Similarly, the highest fentanyl death rates in Ohio's 14 highburden counties occurred among persons aged 25-34 years (10.5 per 100,000) and 35-44 years (9.2), males (5.6), and whites (4.2) as well as persons who were never married/single (8.4) and had less than a high school diploma (9.9) (Table 2). 
Morbidity and Mortality Weekly Report

TABLE 1. Demographic characteristics and toxicology findings for fentanyl-related overdose decedents - Florida, 2010-2012, 2013-2014, and January-June, 2015

\begin{tabular}{|c|c|c|c|c|c|c|}
\hline \multirow[b]{2}{*}{$\begin{array}{l}\text { Demographic characteristics/ } \\
\text { Toxicology findings }\end{array}$} & \multicolumn{2}{|c|}{$\begin{array}{c}2010-2012 \\
(\mathrm{~N}=379)\end{array}$} & \multicolumn{2}{|c|}{$\begin{array}{c}2013-2014 \\
(\mathrm{~N}=582)\end{array}$} & \multirow{2}{*}{$\begin{array}{c}\text { Jan-Jun } 2015 \\
(\mathrm{~N}=289)\end{array}$} & \multirow{2}{*}{$\begin{array}{c}\% \text { change } \\
\text { from } 2010-2012 \text { to } \\
2013-2014\end{array}$} \\
\hline & No. (\%) & $\begin{array}{l}\text { Mean annual rate } \\
\text { per } 100,000\end{array}$ & No. $(\%)$ & $\begin{array}{l}\text { Mean annual rate } \\
\text { per } 100,000\end{array}$ & & \\
\hline Total & $379(100)$ & 0.9 & $582(100)$ & 1.6 & $289(100)$ & $122.1^{*}$ \\
\hline \multicolumn{7}{|l|}{ Age group (yrs) } \\
\hline Mean (SD) & $45.4(12.3)$ & - & $41.1(12.1)$ & - & $40.0(11.6)$ & - \\
\hline $14-25$ & $26(6.9)$ & 0.3 & $59(10.1)$ & 1.0 & $36(12.5)$ & $247.4^{*}$ \\
\hline $26-34$ & $56(14.8)$ & 0.9 & $141(24.2)$ & 3.2 & $70(24.2)$ & $257.0^{*}$ \\
\hline $35-50$ & $147(38.8)$ & 1.2 & $235(40.4)$ & 2.9 & $118(40.8)$ & $143.2^{*}$ \\
\hline$>50$ & $150(39.6)$ & 0.7 & $147(25.3)$ & 1.0 & $65(22.5)$ & $37.0^{*}$ \\
\hline \multicolumn{7}{|l|}{ Sex } \\
\hline Female & $163(43.0)$ & 0.7 & $189(32.5)$ & 1.1 & $84(29.1)$ & $67.6^{*}$ \\
\hline Male & $216(57.0)$ & 0.9 & $393(67.5)$ & 2.5 & $205(70.9)$ & $162.9^{*}$ \\
\hline \multicolumn{7}{|l|}{ Race/Ethnicity ${ }^{\dagger}$} \\
\hline White & $359(94.7)$ & 0.9 & $549(94.3)$ & 2.1 & $270(93.4)$ & $122.5^{*}$ \\
\hline Black & $14(3.7)$ & Exc & $25(4.3)$ & 0.5 & $16(5.5)$ & - \\
\hline Other & $6(1.6)$ & Exc & $8(1.4)$ & Exc & Exc & - \\
\hline \multicolumn{7}{|c|}{ Polysubstance use at time of death ${ }^{\S}$} \\
\hline Prescription opioids & $212(55.9)$ & - & $243(41.8)$ & - & $104(36.0)$ & $-25.4^{*}$ \\
\hline Benzodiazepines** & $198(52.2)$ & - & $289(49.7)$ & - & $107(37.0)$ & -5.0 \\
\hline \multicolumn{7}{|l|}{ Other substances ${ }^{\dagger \dagger}$} \\
\hline Morphine $e^{\S \S}$ & $25(6.6)$ & - & $165(28.4)$ & - & $93(32.2)$ & $329.8^{*}$ \\
\hline Amphetamines & $14(3.7)$ & - & $30(5.2)$ & - & $18(6.2)$ & 39.5 \\
\hline \multicolumn{7}{|l|}{ Illicit substances } \\
\hline Cocaine or Heroin & $66(17.4)$ & - & $242(41.6)$ & - & $158(54.7)$ & $139.1^{*}$ \\
\hline Cocaine & 66 (17.4) & - & $190(32.6)$ & - & $121(41.9)$ & $87.5^{*}$ \\
\hline Heroin & $0(0.0)$ & - & $109(18.7)$ & - & $79(27.3)$ & - \\
\hline Cannabinoids & $30(7.9)$ & - & $61(10.5)$ & - & $49(17.0)$ & 32.4 \\
\hline \multicolumn{7}{|l|}{ Alcohol } \\
\hline Ethanol & 75 (19.8) & - & $133(22.9)$ & - & $63(21.8)$ & 15.5 \\
\hline
\end{tabular}

Abbreviations: Exc = data excluded; $\mathrm{SD}=$ standard deviation.

* $\mathrm{p}<0.05$.

+ Information on Hispanic ethnicity was not available; thus, racial categories include Hispanics and non-Hispanics.

§ Substances consistently reported to the surveillance system during study period: alprazolam, amphetamine, buprenorphine, cannabinoids, carisoprodol/ meprobamate, chlordiazepoxide, clonazepam, cocaine, codeine, diazepam, estazolam, ethanol, fentanyl, flunitrazepam, flurazepam, y-hydroxybutryric acid, helium, heroin, hydrocodone, hydromorphone, ketamine, lorazepam, meperidine, methadone, methamphetamine, midazolam, morphine, nitrous oxide, nordiazepam, oxazepam, oxycodone, oxymorphone, phencyclidine, temazepam, tramadol, triazolam, and zolpidem.

१ Prescription opioids: buprenorphine, codeine, hydrocodone, hydromorphone, meperidine, methadone, oxycodone, oxymorphone, tramadol. Morphine is reported separately.

** Benzodiazepines: alprazolam, chlordiazepoxide, clonazepam, diazepam, estazolam, flunitrazepam, flurazepam, lorazepam, midazolam, nordiazepam, oxazepam, temazepam, and triazolam.

${ }^{+\dagger}$ Includes drugs that are either prescription or illicit drugs.

$\S \S$ Includes decedents who ingested prescription morphine and might include deaths involving heroin.

In Florida, from 2010-2012 to 2013-2014, the percentage of fentanyl deaths testing positive for other illicit substances increased significantly; in particular, fentanyl deaths testing positive for cocaine increased from $17 \%$ to $33 \%$, and fentanyl deaths testing positive for heroin increased from $0 \%$ to $19 \%$. This trend continued into the first half of 2015, with 55\% of fentanyl decedents testing positive for heroin or cocaine compared with 42\% during 2013-2014. The percentage of fentanyl deaths testing positive for morphine in Florida increased significantly from 2010-2012 (7\%) to 2013-2014 (28\%) (Table 1). Finally, fentanyl analogs were implicated in 49 fatal drug overdoses in Florida during January-June 2015, including acetyl fentanyl (26), butyryl fentanyl (five), and beta-hydroxythiofentanyl (18).

In Ohio's 14 high-burden counties, 56\% of fentanyl deaths tested positive for heroin or cocaine in 2014, with 39\% testing positive for heroin and $23 \%$ for cocaine (Table 2). In-depth examination of medical examiner and coroner records in these high-burden counties revealed that emergency medical services responded to $82 \%$ of fentanyl deaths, at least one bystander was present in $72 \%$ of cases, and $41 \%$ of decedents received treatment in the field with naloxone (Table 2). Other characteristics of fentanyl deaths included current diagnosed mental health disorder (25\%) and recent release (within 30 days) from a jail, hospital, or treatment facility (10.3\%) (Table 2 ). 
TABLE 2. Selected characteristics of fentanyl-related overdose decedents $(N=456)-14$ Ohio counties, 2014

\begin{tabular}{|c|c|c|}
\hline Characteristic & No. (\%) & $\begin{array}{l}\text { Rate per } \\
100,000\end{array}$ \\
\hline \multicolumn{3}{|l|}{$\mathrm{Sex}^{*}$} \\
\hline Female & $137(30.0)$ & 2.3 \\
\hline Male & $319(70.0)$ & 5.6 \\
\hline \multicolumn{3}{|l|}{ Race* } \\
\hline White & $407(89.3)$ & 4.2 \\
\hline Black & $43(9.4)$ & 2.8 \\
\hline \multicolumn{3}{|l|}{ Age group (yrs)* } \\
\hline $15-24$ & $48(10.5)$ & 3.1 \\
\hline 25-34 & $154(33.8)$ & 10.5 \\
\hline $35-44$ & $130(28.5)$ & 9.2 \\
\hline $45-54$ & $79(17.3)$ & 4.9 \\
\hline$\geq 55$ & $45(9.9)$ & 1.3 \\
\hline \multicolumn{3}{|l|}{ Marital status* } \\
\hline Never married/Single & $244(54.0)$ & 8.4 \\
\hline Divorced, separated, widowed & $130(28.8)$ & 6.8 \\
\hline Married & $78(17.3)$ & 1.7 \\
\hline \multicolumn{3}{|l|}{ Education ( $\geq 25 \mathrm{yrs})^{*}$} \\
\hline Less than high school diploma & $86(21.5)$ & 9.9 \\
\hline $\begin{array}{l}\text { High school or General Educational } \\
\text { Development }\end{array}$ & $212(53.0)$ & 7.9 \\
\hline Some college & $58(14.5)$ & 3.6 \\
\hline Associate's degree or higher & $44(11.0)$ & 1.7 \\
\hline \multicolumn{3}{|c|}{ Current diagnosed mental health disorder ${ }^{\dagger}$} \\
\hline Yes & $103(25.0)$ & - \\
\hline No & $309(75.0)$ & - \\
\hline \multicolumn{3}{|c|}{$\begin{array}{l}\text { Recent (in preceding } 30 \text { days) release from a jail, } \\
\text { rehabilitation facility, or hospital }{ }^{\S}\end{array}$} \\
\hline Overall & $47(10.3)$ & - \\
\hline Jail, prison, or detention facility & $19(40.4)$ & - \\
\hline $\begin{array}{l}\text { Residential substance use disorder } \\
\text { treatment }\end{array}$ & $16(34.0)$ & - \\
\hline Hospital & $9(19.1)$ & - \\
\hline \multicolumn{3}{|l|}{ Response to fentanyl overdose ${ }^{\pi}$} \\
\hline Bystanders present & $251(72.3)$ & - \\
\hline Emergency medical services responded & $375(82.2)$ & - \\
\hline Naloxone administered & $161(40.8)$ & - \\
\hline \multicolumn{3}{|l|}{ Polysubstance use at time of death** } \\
\hline Tested positive for cocaine & $105(23.0)$ & - \\
\hline Tested positive for heroin & $177(38.8)$ & - \\
\hline
\end{tabular}

* Because of the low number of missing values for each of these variables, percentages for these were calculated for fentanyl deaths with known information.

† "Yes" indicates that the decedent had been identified during the death investigation as having a mental health disorder or syndrome listed in the Diagnostic and Statistical Manual, Version IV (DSM-IV). Alcohol and other substance dependence are excluded from this variable.

$\S$ Type of institution was not known for one decedent, and fewer than five decedents had been released from other types of facilities.

" Information was abstracted from death scene investigations and might be underestimated.

** Fewer than five decedents did not have toxicology information.

\section{Discussion}

The findings in this report suggest the need to improve fentanyl death surveillance with a focus on distinguishing deaths involving IMF and PF, and enhancing public health support of persons using heroin through increased access to medicationassisted treatment and expanded access to the opioid antagonist naloxone. Although toxicologic panels cannot distinguish IMF from PF, the findings suggest that the surges in fentanyl deaths in Florida and Ohio during 2013-2015 were closely related to increases in the IMF supply, as opposed to diverted PF. This is supported by multiple factors including 1) the stability in prescribing and dispensing of PF in Florida and Ohio, even as fentanyl deaths sharply increased; 2) the implication of acetyl fentanyl and beta-hydroxythiofentanyl, both illicitly produced fentanyl analogs, in a significant number of fentanyl deaths in Florida; 3) recent DEA reports linking most U.S. fentanyl deaths to IMF (4); 4) demographic characteristics of fentanyl decedents in Ohio and changes in the demographic characteristics of fentanyl decedents from 2010-2012 to 2013-2014 in Florida were similar to heroin decedents nationally; and 5) interviews with persons using illicit drugs in Ohio indicating that fentanyl appears to be mixed with or sold as heroin. ${ }^{\dagger \dagger}$ DEA reports have noted that IMF is often mixed with heroin, and then sold as a heroin product on the illicit market $(1,4)$. In Ohio and Florida, a substantial proportion of fentanyl decedents tested positive for heroin (39\% and 19\%, respectively); it is likely that this represents an underascertainment, because heroin is quickly metabolized to morphine, thus morphinepositive fentanyl deaths can indicate prescription morphine or metabolism of heroin (5).

The changing demographics of fentanyl decedents in Florida from 2010-2012 to 2013-2014 and the demographics of fentanyl decedents in Ohio in 2014 mirror the evolving demographics of persons who use heroin in the United States. ${ }^{\mathbb{S}}$ Risk profiles changed notably during the current epidemic, with fentanyl deaths in Florida increasing almost 2.5 times faster among men (163\%) than women (68\%), with the most rapidly increasing rate among persons aged 14-34 years. In contrast, U.S. death rates involving prescription opioids are highest among persons aged 45-54 years, a slightly older group than this cohort of fentanyl decedents (6). In addition, the demographic of fentanyl decedents in Ohio closely matched those of heroin overdose decedents, but diverged from prescription opioid overdose decedents.

The findings in this report are subject to at least five limitations. First, since toxicologic panels cannot distinguish between $\mathrm{PF}$ and IMF, this study does not provide precise counts of overdoses involving IMF compared with PF. Second, the numbers and rates of fentanyl deaths are underestimated because not all overdose deaths were tested for fentanyl and testing for fentanyl analogs is not systematic statewide in either state. Third, NFLIS data might vary over time and geography because of differences or changes in law enforcement testing practices

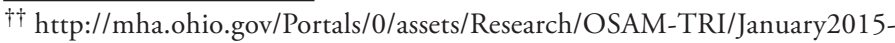
fullReport.pdf.

$\$ \$$ http://www.cdc.gov/nchs/products/databriefs/db190.htm.
} 


\section{Summary}

What is already known about this topic?

In 2015, the Drug Enforcement Agency and CDC issued nationwide alerts identifying increases in fentanyl-related overdose deaths (fentanyl deaths) in multiple states. Although prescription fentanyl can be diverted for misuse, most fentanyl overdoses and deaths have been linked to illicitly manufactured fentanyl (IMF), including fentanyl analogs. Multiple states that experienced increases in law enforcement submissions to laboratories of drug products that tested positive for fentanyl during 2013-2014 also reported sharp increases in fentanyl deaths.

What is added by this report?

Analyses of 2013-2015 data from Florida and Ohio indicated that sharp increases in fentanyl deaths were associated with significant increases in the supply of IMF in these states, with fentanyl analogs detected in the Florida illicit market. Novel circumstances surrounding fentanyl mortality included current diagnosed mental health disorder and release from an institutional facility (e.g., a jail, treatment facility, or hospital) within the preceding 30 days. The risk profiles of fentanyl overdose decedents were similar to those of persons dying from heroin overdose.

What are the implications for public health practice?

The rapid increases in fentanyl deaths in Florida and Ohio illustrate the need to intensify efforts to expand use of naloxone. Increased naloxone access, particularly among community members, is critical given fentanyl's potency and the possibility of causing rapid death. The relationship between fentanyl deaths and increases in the supply of IMF suggests that law enforcement testing data on drug cases could serve as an early warning system to detect variations in overdose risk related to changes in the drug supply. Multidisciplinary strategies from public health agencies, harm reduction communities, emergency medical services, law enforcement, and treatment services for substance use disorders might have the greatest impact on public health, given the close relationship between fentanyl mortality and confiscation of IMF.

and enforcement activity. Fourth, part of this investigation was limited to abstraction of information collected during the medical examiner and coroner death investigation, and information collected might vary among counties within both states. Finally, analysis of medical examiner and coroner records was limited to high-burden counties in Ohio, and findings might not be generalizable to the entire state.

The rapid increase in fentanyl deaths indicates the need for timely surveillance and response. The relationship between fentanyl deaths and fentanyl submissions in both Florida and Ohio suggests that fentanyl submissions data could act as an early warning system to identify changes in the illicit drug supply. Distinguishing whether an overdose involves IMF or PF is critical for targeted interventions because overdose risk profiles differ. Additional work is needed to determine the extent to which medical examiners and coroners can use decedents' substance use history, scene evidence (e.g., white powder consistent with IMF or patches consistent with PF), toxicology (e.g., presence of heroin or cocaine), and prescription drug monitoring program data to distinguish IMF from PF overdoses. Similar to national NFLIS data, Florida began detecting increases in fentanyl analog submissions in 2015. Because the lethality of fentanyl analogs vary, increased testing for analogs in areas experiencing large numbers of fentanyl deaths or increases in overdose deaths might be needed.

The U.S. Department of Health and Human Services has launched an initiative to reduce opioid misuse and overdose by expanding medication-assisted treatment, increasing the availability and use of naloxone, and promoting safer opioid prescribing. 99 Past misuse of prescription opioids is the strongest risk factor for heroin initiation and use, particularly among persons who report past-year dependence or abuse (7).

The rapid increase in fentanyl deaths in Florida and Ohio illustrates the high potency of fentanyl, with the possibility of rapid death (8), highlighting the importance of quickly recognizing an overdose, calling 9-1-1 promptly, facilitating rapid administration of $\geq 1$ naloxone doses, and the need to expand naloxone availability. The presence of bystanders in Ohio suggests the opportunity to improve overdose response including increasing support for community naloxone distribution programs. In Ohio, naloxone was administered in four of 10 cases. Multiple doses of naloxone and/or emergency medical treatment might be needed to reverse a fentanyl overdose. Community members might want to have several naloxone doses available and should be instructed to call 9-1-1 immediately, even when administering naloxone (2).***

Linkage and access to treatment and to naloxone are needed for persons at high risk. In Ohio, a significant percentage of fentanyl deaths involved persons recently released from an institution and persons with a current diagnosed mental health disorder, placing both groups at increased risk for overdose. Persons recently released from an institution are at particularly high risk for opioid overdose because of lowered opioid tolerance resulting from abstinence during residential treatment or incarceration (9). Interventions such as provision of naloxone and continuation of medication-assisted treatment after release have been shown to be effective for this group (10).

\footnotetext{
99 https://aspe.hhs.gov/sites/default/files/pdf/107956/ib_OpioidInitiative.pdf *** http://store.samhsa.gov/shin/content//SMA16-4742/SMA16-4742.pdf.
} 


\section{Acknowledgments}

Luke Werhan, Kelli Redd, Kara Manchester, Katelyn Yoder, Ohio Department of Health.

\footnotetext{
${ }^{1}$ Epidemic Intelligence Service, CDC; ${ }^{2}$ Division of Unintentional Injury Prevention, National Center for Injury Prevention and Control, CDC; ${ }^{3}$ Division of Analysis, Research, and Practice Integration, National Center for Injury Prevention and Control, CDC; ${ }^{4}$ Department of Health Outcomes and Policy, College of Medicine, University of Florida, Gainesville, Florida; ${ }^{5}$ Division of Violence Prevention, National Center for Injury Prevention and Control, CDC; ${ }^{6}$ Department of Pathology, Immunology, and Laboratory Medicine, College of Medicine, University of Florida, Gainesville, Florida;

${ }^{7}$ Division of Scientific Education and Professional Development, CDC; ${ }^{8}$ Ohio Department of Health.
}

Corresponding authors: Alexis Peterson, apeterson4@cdc.gov, 770-488-0767;

R. Matthew Gladden, mgladden@cdc.gov, 770-488-4276.

\section{References}

1. Drug Enforcement Administration. DEA issues nationwide alert on fentanyl as threat to health and public safety. Washington, DC: US Department of Justice, Drug Enforcement Administration; 2015. https:// www.dea.gov/divisions/hq/2015/hq031815.shtml

2. CDC. CDC health advisory: increases in fentanyl drug confiscations and fentanyl-related overdose fatalities. Atlanta, GA: US Department of Health and Human Services, CDC; 2015. http://emergency.cdc.gov/ han/han00384.asp
3. Gladden RM, Martinez P, Seth P. Fentanyl law enforcement submissions and increases in synthetic opioid-involved overdose deaths - 27 states, 2013-2014. MMWR Morb Mortal Wkly Rep 2016;65:837-43.

4. Drug Enforcement Administration. DEA intelligence report: national heroin threat assessment summary-updated. Washington, DC: US Department of Justice, Drug Enforcement Administration; 2016. https:// www.dea.gov/divisions/hq/2016/hq062716_attach.pdf

5. Harruff RC, Couper FJ, Banta-Green CJ. Tracking the opioid drug overdose epidemic in King County, Washington using an improved methodology for certifying heroin-related deaths. Academy Forensic Pathology 2015;5:499-506.

6. Paulozzi LJ, Jones CM, Mack KA, Rudd RA. Vital signs: overdoses of prescription opioid pain relievers-United States, 1999-2008. MMWR Morb Mortal Wkly Rep 2011;60:1487-92.

7. Jones CM, Logan J, Gladden RM, Bohm MK. Vital signs: demographic and substance use trends among heroin users-United States, 2002_ 2013. MMWR Morb Mortal Wkly Rep 2015;64:719-25.

8. Peng PW, Sandler AN. A review of the use of fentanyl analgesia in the management of acute pain in adults. Anesthesiology 1999;90:576-99. http://dx.doi.org/10.1097/00000542-199902000-00034

9. Merrall EL, Kariminia A, Binswanger IA, et al. Meta-analysis of drugrelated deaths soon after release from prison. Addiction 2010;105:154554. http://dx.doi.org/10.1111/j.1360-0443.2010.02990.x

10. Hawk KF, Vaca FE, D'Onofrio G. Reducing fatal opioid overdose: prevention, treatment and harm reduction strategies. Yale J Biol Med 2015;88:235-45. 